\title{
(6) OPEN ACCESS \\ Health trajectories in regeneration areas in England: the impact of the New Deal for Communities intervention
}

\author{
Pierre Walthery, ${ }^{1}$ Mai Stafford ${ }^{2}{ }^{2}$ James Nazroo, ${ }^{1}$ Margaret Whitehead, ${ }^{3}$ \\ Christopher Dibben, ${ }^{4}$ Emma Halliday, ${ }^{5}$ Sue Povall, ${ }^{3}$ Jennie Popay ${ }^{5}$
}

${ }^{1}$ Cathie Marsh Centre for Census and Survey Research, University of Manchester, Manchester, UK ${ }^{2} \mathrm{MRC}$ Unit for Lifelong Health and Ageing at $\mathrm{UCL}, \mathrm{UCL}$, London, UK

${ }^{3}$ Institute of Psychology, Health and Society, University of

Liverpool, Liverpool, UK

${ }^{4}$ Department of Geography and

Sustainable Development,

University of St Andrews,

St Andrews, UK

${ }^{5}$ Division of Health Research

University of Lancaster,

Lancaster, UK

\section{Correspondence to} Dr Pierre Walthery, Cathie Marsh Centre for Census and Survey Research, Humanities Bridgeford St Building, University of Manchester, Oxford Road, Manchester M13 9PL, UK;

pierre.walthery@manchester.ac. uk

Received 8 May 2014 Revised 10 November 2014 Accepted 29 December 2014 Published Online First 17 June 2015

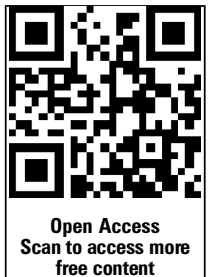

\section{CrossMark}

To cite: Walthery $\mathrm{P}$,

Stafford M, Nazroo J, et al. J

Epidemiol Community Health 2015;69:762-768.

\section{ABSTRACT}

Background A large body of evidence documents the adverse relationship between concentrated deprivation and health. Among the evaluations of regeneration initiatives to tackle these spatial inequalities, few have traced the trajectories of individuals over time and fewer still have employed counterfactual comparison. We investigate the impact of one such initiative in England, the New Deal for Communities (NDC), which ran from 1999 to 2011, on socioeconomic inequalities in health trajectories.

Methods Latent Growth Curve modelling of withinperson changes in self-rated health, mental health and life satisfaction between 2002 and 2008 of an analytical cohort of residents of 39 disadvantaged areas of England in which the NDC was implemented, compared with residents of comparator, non-intervention areas, focusing on: (1) whether differences over time in outcomes can be detected between NDC and comparator areas and (2) whether interventions may have altered socioeconomic differences in outcomes.

Results No evidence was found for an overall improvement in the three outcomes, or for significant differences in changes in health between respondents in NDC versus comparator areas. However, we found a weakly significant gap in life satisfaction and mental health between high and low socioeconomic status individuals in comparator areas which widened over time to a greater extent than in NDC areas. Change over time in the three outcomes was non-linear: individual improvements among NDC residents were largest before 2006.

Conclusions There is limited evidence that the NDC moderated the impact of socioeconomic factors on mental health and life satisfaction trajectories. Furthermore, any NDC impact was strongest in the first 6 years of the programmes.

\section{INTRODUCTION}

The relationships between health, disadvantaged socioeconomic circumstances and their concentration in particular geographical areas have become a mainstream issue in UK policy. This is reflected in the successive publication of the Black and Acheson reports and the recent Marmot review. ${ }^{1-3}$ These have stressed that although population health has been improving in the UK since World War II, inequalities in health between different socioeconomic groups have persisted, and in some cases widened. ${ }^{1-3}$ As a result, health inequalities between regions and smaller areas remain substantial: for instance, there was a 9-year gap in male life expectancy at birth in $2009 / 2011^{4}$ and a $12 \%$ difference in the proportion of people with bad or very bad self-rated health ${ }^{5}$ between local authorities in England. In addition, area of residence is associated with health outcomes independently of individual characteristics. ${ }^{67}$ Poor quality of the built environment, high unemployment, low social capital and inadequate access to public and private transport are all associated with low self-rated health, mental health and life satisfaction. ${ }^{8-11}$

\section{The New Deal for Communities and Area Based Interventions}

In order to reduce inequalities in health and its social determinants, successive governments in England have used spatially targeted policies-commonly known as Area Based Interventions (ABIs) - dating back to the 1960s. The latest and possibly most ambitious of such ABIs was the New Deal for Communities (NDC), a large-scale regeneration initiative implemented in 39 of the most deprived areas of England between 1998 and 2011. ${ }^{12}$ Population varied between 4800 and 21400 with an average size of $9900 .^{13}$ The overall goal of the NDC was to reduce inequalities between these areas and the rest of England in three area-based outcome domains (crime, community, and environment and housing) and three person-based outcome domains (education, worklessness and health). ${ }^{13}$ Overall, only $11 \%$ of the total funding was spent on health-related projects, most of which had to do with improving access to health services. ${ }^{14}$ The NDC consisted of a set of decentralised interventions aiming at improving the wider social determinants of health inequalities. A strong focus on partnership between local agencies (notably the local authority and NHS organisations) and local residents was a pre-requisite for funding. Each NDC area received around $£ 50$ million between 1999 and 2011. This represented an unparalleled long-term commitment by English policy standards. ${ }^{14}$ Funding was also awarded to a National Evaluation Team (NET), which produced a series of reports on the impact of the NDC and a rich legacy of data sources.

Results from the NET indicate that NDC areas experienced an overall improvement between 2002 and 2008, measured as a cumulative index of 36 indicators (including perceptions of the area, educational attainment, employment and training, health behaviours and mental health) aggregated in each area. This was, however, modest in size and more noticeable on place-based outcomes. ${ }^{15}$ Evidence of withinperson change is limited, but among these, improvement in self-rated health was most noticeable: $46 \%$ of residents of NDC areas reported an improvement in 
their self-rated health against $31 \%$ in comparator areas between 2002 and $2008,{ }^{15}$ not controlling for socioeconomic or demographic factors. Differences in mental health were smaller with $48 \%$ of NDC residents experiencing an improvement, against $43 \%$ in comparator areas. ${ }^{16}$ In comparator as well as NDC areas, a similar proportion saw their self-rated and mental health worsen during the same period. However, differences in improvement in mental health between NDC and comparator areas disappeared following adjustment for baseline health and socioeconomic differences. ${ }^{17}$

Between 2002 and 2008, poor outcomes were reduced by the greatest amount in less-deprived NDC areas, NDCs where other concurrent or previous ABIs overlapped, and areas characterised as predominantly 'White', peripheral housing estates, in non-core cities. ${ }^{14} 18$ Other studies also suggest that the associations between neighbourhood characteristics and health could be moderated by factors such as resident's unemployment, socioeconomic circumstances, ethnicity and housing tenure. ${ }^{8}{ }^{19-21} \mathrm{We}$ consider whether individual socioeconomic factors moderate the impact of the NDC intervention on health outcomes.

The study reported here compares the individual self-rated health, mental health and life satisfaction trajectories of residents in NDC areas between 2002 and 2008 with those living in similarly disadvantaged comparator areas. There are multiple social determinants of these outcomes, so they are plausibly able to capture an NDC impact operating through improvements in crime, community, environment and housing, education, worklessness, and healthcare. ${ }^{22} 23$ Specifically, the study aimed (1) to determine whether there is an overall effect of the NDC programme on these outcomes and their change over time; (2) to test whether there was a differentiated impact of the NDC intervention on specific socioeconomic groups, namely those with low education, in jobless households or renting their home.

\section{METHODS}

Data consisted of a household panel survey carried out in 2002, 2004, 2006 and 2008 in each of the 39 NDC areas, with a target sample size of 500 respondents per area. The cross-sectional response rate was 74\%. From 2004, top-up cross-sectional interviews were conducted at each wave to compensate for attrition. In 2006, the sample size was reduced by one-fifth, as part of costsaving measures. Primary sampling units were addresses within which dwelling, households and one respondent aged 16 years or more were randomly selected. Interviews were administered face to face. Data were also collected from non-contiguous disadvantaged comparator areas within the same local authority with an overall targeted size of 3000 respondents ( 77 in each area).

In order to maximise the potential exposure to the intervention, we restricted the study to respondents who provided data on at least two occasions and were resident in NDC or comparator areas at wave 1 (2002). Sensitivity analyses comparing respondents with only one record (not presented here) indicated very similar estimates for all outcomes considered. Sample size was 10638 in NDC areas, and 1010 in comparator areas. Weights correcting for unequal probability of selection and size of NDC areas were used. ${ }^{24}$

\section{Variables}

Three health-related outcomes were analysed among the few relevant that were available in the survey:

- A single-item variable captured self-rated health (Over the last 12 months, would you say that your health has on the whole been good, fairly good or not good?), with possible answers being 'Very good', 'Fairly good', 'Not good'.
- The Mental Health Inventory (MHI-5) $)^{25}$ measured five aspects of mental well-being on five category scales. Respondents were asked whether in the past 4 weeks they had 'been a very nervous person', 'felt down in the dumps', 'been a happy person', 'felt calm and peaceful', 'felt downhearted and low'.

- A single-item variable captured life satisfaction (If we were to define "quality of life" as how you feel overall about your life, including your standard of living, your surroundings, friendships and how you feel day-to-day, how would you rate your quality of life?) with five possible responses ranging from 'Very satisfied' to 'Very dissatisfied'.

Demographic factors included self-defined ethnicity (using the 2001 English Census question), whether they were married or cohabiting, and the presence of dependent children in the household. Socioeconomic factors included educational attainment as a three-category indicator: national vocational qualification (NVQ) $4-5$ or equivalent, $2-3$, and 1 or less. NVQ1 is to GCSE level and NVQ4 is up to degree level. Respondents also reported their housing tenure (privately rented or social housing vs owner-occupancy), and whether anyone in the household was in paid employment. Although this did not distinguish retired respondents, we also controlled for age.

\section{Modelling strategy}

An Item Response Theory model was fitted to the five mental health items of the MHI-5, because of a general reservation about the robustness of cumulative scores, as well as the skewed distribution of the responses. The derived scores were subsequently used as outcomes in three separate Latent Growth models (one for each outcome). ${ }^{26}$ Such models are suitable for ordinal outcomes, here self-rated health and life satisfaction. In this modelling framework, the outcomes at four measurement occasions were used to estimate two factors which define the parameters of a growth line, namely its intercept and slope. The former represents the average value at baseline, while the latter captures the average rate of change between the first and the last wave. Possible non-linearity of the change in outcome was tested by estimating whether up to two loadings of the slope factors were significantly different from their default 'linear' value. ${ }^{27}$ Models were estimated using the MPlus software package. ${ }^{28}$

For each outcome, intercept and slope differences for NDC versus comparator areas were estimated in three sequentially adjusted models: (1) demographic factors (gender, age, ethnicity, cohabitation status and dependent children in household) (model 1) and (2) demographic and socioeconomic factors (educational attainment, jobless household and housing tenure) (model 2). In order to assess whether the NDC moderated the impact of socioeconomic factors on outcomes, we added interaction terms for comparator by education, comparator by joblessness and comparator by housing tenure (model 3).

\section{RESULTS}

\section{Descriptive results}

Table 1 shows that comparator and intervention areas differed with respect to their demographic and socioeconomic characteristics at baseline (2002). Respondents in NDC areas were more likely to be female, cohabitating, have dependent children, have low educational attainment, and less likely to own their home than those in comparator areas. No differences in ethnicity or joblessness were found between NDC and comparator areas.

\section{Model results: overall NDC effect}

Table 2 provides the results of the latent growth models. The mean value of the slope of the growth lines (bottom of the 
Table 1 Characteristics of residents in NDC intervention and comparator areas at baseline (2002)

\begin{tabular}{|c|c|c|c|c|}
\hline & \multicolumn{2}{|c|}{ NDC sample } & \multicolumn{2}{|c|}{ Comparator sample } \\
\hline & Per cent & $95 \% \mathrm{Cl}$ & Per cent & $95 \% \mathrm{Cl}$ \\
\hline $\begin{array}{l}\text { In good self-reported } \\
\text { health }\end{array}$ & 40.4 & 39.3 to 41.4 & 40.7 & 37.3 to 44.2 \\
\hline $\begin{array}{l}\text { Very/fairly good life } \\
\text { satisfaction }\end{array}$ & 78.1 & 76.1 to 80.0 & 81.4 & 74.9 to 88.1 \\
\hline $\begin{array}{l}\text { Mean MHI-5 mental } \\
\text { health score* }\end{array}$ & 71.4 & 71.0 to 71.8 & 73.1 & 71.7 to 74.5 \\
\hline Female & 59.7 & 58.7 to 60.8 & 54.1 & 50.6 to 57.5 \\
\hline Cohabiting & 30.6 & 29.7 to 31.4 & 27.0 & 24.5 to 29.6 \\
\hline Dependent children & 37.3 & 36.3 to 38.3 & 37.1 & 33.9 to 40.5 \\
\hline NVQ 1 or below & 58.0 & 57.0 to 59.1 & 53.6 & 50.2 to 57.1 \\
\hline NVQ 2 or 3 & 28.6 & 27.6 to 29.6 & 32.7 & 29.6 to 36.1 \\
\hline NVQ 4 or 5 & 13.4 & 12.7 to 14.1 & 13.6 & 11.5 to 16.1 \\
\hline Rents accommodation & 58.8 & 57.8 to 59.8 & 43.2 & 39.9 to 46.6 \\
\hline Non-white & 23.3 & 22.4 to 24.1 & 19.0 & 16.3 to 22.1 \\
\hline Jobless household & 43.1 & 42.1 to 44.1 & 39.2 & 36.1 to 42.5 \\
\hline Mean age & 46.0 & 45.6 to 46.3 & 47.7 & 46 to $5-48.9$ \\
\hline
\end{tabular}

table) shows that no significant overall change over time in any of the outcomes was found. The overall change in mental health between 2002 and 2008 was 0.07 SDs (95\% CI -0.18 to 0.32 ). Individuals differed significantly in their baseline levels of mental health and their rate of change over time (indicated by statistically significant intercept and slope variances at the 0.001 level). Respondents worse off at baseline were those most likely to experience an improvement over time, as indicated by the negative covariance term at the bottom of table 2 .

For each of the three outcomes included in the growth models-mental health, self-rated health and life satisfactionthe first column in table 2 describes estimates adjusting for demographic characteristics (model 1), and the second column presents the estimates, additionally adjusting for socioeconomic variables (model 2). Regression coefficients for the baseline levels of the outcomes are shown in the top section of the table, whereas the middle section of table 2 shows the relationship between covariates and change in each outcome over time.

\section{Mental health adjusted for demographic factors}

At baseline (2002), residents in comparator areas had better mental health (by 0.02 SDs of the mental health latent variable, 95\% CI 0.00 to 0.04 ) than those in NDC intervention areas, after adjusting for demographic factors. Women's mental health was poorer than that of men and parents of dependent children also had poorer mental health than those without dependent children, whereas non-white respondents as well as those married or cohabiting enjoyed better mental health than white respondents and those not married or cohabiting.

The slope coefficient of the mental health outcome was not statistically significant, indicating no overall change between 2002 and 2008 among residents of NDC areas as a whole. Similarly, the slope regression coefficient indicated no change over time in comparator areas. Women, however, experienced a greater improvement in mental health than men, and those cohabiting experienced a smaller improvement than those not cohabiting.
Mental health adjusted for demographic and socioeconomic factors

Socioeconomic factors were strongly related to mental health at baseline. Those with NVQ level 1 or below, those renting their home and those living in a jobless household had worse mental health than those with higher educational attainment, home owners and those in working households. Joblessness had the largest impact with $-0.17 \mathrm{SD}$, against 0.08 and 0.09 for education and home ownership. Socioeconomic factors explained the small mental health advantage of those in comparator areas at baseline. Household joblessness was the only one of the socioeconomic factors associated (at the 0.1 level) with an improvement in mental health over time.

Models for self-rated health

Self-rated health at baseline was better in comparator areas than in NDC intervention areas, after adjusting for demographic factors. Further adjustment for socioeconomic factors attenuated this advantage. We found that there was neither evidence of an overall improvement nor a worsening in self-rated health in NDC or comparator areas-in other words, no comparator vs NDC main effect. However, in the fully adjusted model (model 2), older age was associated with declining self-rated health, whereas living in a jobless household was again the only socioeconomic factor associated with an improvement $(\mathrm{p}<0.01)$.

\section{Models for life satisfaction}

Life satisfaction at baseline was higher in comparator areas than in NDC intervention areas, after adjusting for demographic factors (model 1) and socioeconomic factors (model 2). There was no evidence of overall change in life satisfaction in NDC or comparator areas. The lower educated seem to experience a decrease in their life satisfaction over time $(p=0.01)$.

\section{Differentiated impact of NDC intervention by socioeconomic group}

We further tested whether the association between socioeconomic factors and health and life satisfaction trajectories differed between residents in NDC and comparator areas with interaction terms. Estimates are shown in table 2 and significant interactions are illustrated in figure 1. Models suggest that residents in poorer socioeconomic circumstances at baseline may have experienced smaller improvements in comparator areas than their counterparts in NDC intervention areas, as detailed in table 2. For mental health, those living in rented accommodation experienced a higher improvement than owner-occupiers in NDC areas (or said otherwise, the gap did not narrow in comparator areas), even if the main effect was not significant. To a lesser extent, those with the lowest level of education (NVQ 1 or below) experienced a significantly smaller increase (0.09 SD, $\mathrm{p}<0.05$ ) in life satisfaction than the highly educated in comparator areas. In NDC areas, there was no evidence of differential rates of improvement in life satisfaction by education level. There was no evidence of interactions between NDC and socioeconomic factors for self-rated health (data available from the authors).

\section{Shape of change over time}

Against the default assumption of linear change over time, which is operationalised by fixing the slope factor loadings at 0 , 1,2 and 3, respectively, the hypothesis of non-linear growth patterns was tested by freeing the factor loadings for the third time point (ie, 2006). These models were a significantly better 
Table 2 Latent Growth Curve models of mental health, self-rated health and life satisfaction in NDC and comparator areas based on 11648 residents

\begin{tabular}{|c|c|c|c|c|c|c|c|c|c|c|c|}
\hline \multicolumn{4}{|c|}{ Mental health $t$} & \multicolumn{4}{|c|}{ Self-rated health $\neq$} & \multicolumn{4}{|c|}{ Life satisfaction§ } \\
\hline \multicolumn{2}{|c|}{ Model 1} & \multicolumn{2}{|c|}{ Model 2} & \multicolumn{2}{|c|}{ Model 1} & \multicolumn{2}{|c|}{ Model 2} & \multicolumn{2}{|c|}{ Model 1} & \multicolumn{2}{|c|}{ Model 2} \\
\hline Coef & SE & Coef & SE & Coef & SE & Coef & SE & Coef & SE & Coef & SE \\
\hline
\end{tabular}

Factors affecting outcomes in 2002: baseline (intercept) regression coefficients

\begin{tabular}{|c|c|c|c|c|c|c|c|c|c|c|c|c|}
\hline & & & & & & & & & & & & \\
\hline Comparator & 0.029 & $(0.01)$ & 0.01 & $(0.01)$ & $0.03^{*}$ & $(0.01)$ & 0.01 & $(0.01)$ & $0.05^{* \star \star}$ & $(0.02)$ & $0.04^{*}$ & $(0.02)$ \\
\hline Female & $-0.18^{* * *}$ & $(0.01)$ & $-0.17^{* * *}$ & $(0.01)$ & $-0.03^{*}$ & $(0.01)$ & -0.02 & $(0.01)$ & $0.04^{*}$ & $(0.02)$ & $0.05^{* *}$ & $(0.02)$ \\
\hline Age & 0.02 & $(0.02)$ & $0.10^{* * *}$ & $(0.02)$ & $-0.37^{* * *}$ & $(0.01)$ & $-0.27^{* * *}$ & $(0.02)$ & -0.01 & $(0.02)$ & 0.039 & $(0.02)$ \\
\hline Non-white & $0.06^{* * *}$ & $(0.02)$ & $0.05^{* * *}$ & $(0.01)$ & 0.02 & $(0.01)$ & 0.01 & $(0.01)$ & $-0.05^{* *}$ & $(0.02)$ & $-0.05^{* * *}$ & $(0.02)$ \\
\hline Cohabits & $0.11^{* * *}$ & $(0.01)$ & $0.05^{* * *}$ & $(0.01)$ & $0.08^{* * *}$ & $(0.01)$ & 0.00 & $(0.01)$ & $0.11^{* * *}$ & $(0.02)$ & $0.05^{* *}$ & $(0.02)$ \\
\hline Dependent children & $-0.06^{* * *}$ & $(0.02)$ & $-0.04^{*}$ & $(0.02)$ & -0.02 & $(0.02)$ & -0.01 & $(0.02)$ & $-0.14^{* * *}$ & $(0.02)$ & $-0.11^{* * *}$ & $(0.02)$ \\
\hline NVQ 1 or below & - & - & $-0.08^{* * *}$ & $(0.02)$ & - & - & $-0.09^{* * *}$ & $(0.02)$ & - & - & 0.02 & $(0.02)$ \\
\hline NVQ 2-3 & - & - & -0.02 & $(0.02)$ & - & - & $-0.05^{* *}$ & $(0.02)$ & - & - & 0.01 & $(0.02)$ \\
\hline Jobless household & - & - & $-0.17^{* * *}$ & $(0.02)$ & - & - & $-0.21 * * *$ & $(0.02)$ & - & - & $-0.11^{* * *}$ & $(0.02)$ \\
\hline Rents & - & - & $-0.09^{* * *}$ & $(0.02)$ & - & - & $-0.10^{* * *}$ & $(0.01)$ & - & - & $-0.13^{* * *}$ & $(0.02)$ \\
\hline Factors affecting changes in & outcome ove & time: & e regression & oefficien & & & & & & & & \\
\hline Comparator & -0.04 & $(0.03)$ & -0.04 & $(0.03)$ & -0.01 & $(0.03)$ & -0.02 & $(0.04)$ & 0.01 & $(0.04)$ & 0.01 & $(0.04)$ \\
\hline Female & $0.13^{* * *}$ & $(0.03)$ & $0.12^{* * *}$ & $(0.03)$ & 0.01 & $(0.04)$ & 0.01 & $(0.04$ & 0.02 & $(0.04)$ & 0.02 & (0.04) \\
\hline Age & -0.03 & $(0.04)$ & -0.06 & $(0.04)$ & $-0.08+$ & $(0.05)$ & $-0.10^{*}$ & $(0.05)$ & 0.01 & $(0.04)$ & 0 & $(0.05)$ \\
\hline Non-white & -0.02 & $(0.03)$ & -0.02 & $(0.03)$ & -0.06 & $(0.04)$ & $-0.07+$ & $(0.04)$ & 0.05 & $(0.04)$ & 0.05 & $(0.04)$ \\
\hline Cohabits & $-0.07^{*}$ & $(0.03)$ & -0.05 & $(0.03)$ & -0.00 & $(0.03)$ & 0.02 & $(0.04)$ & -0.02 & $(0.04)$ & -0.02 & $(0.04)$ \\
\hline Dependent children & -0.03 & $(0.04)$ & -0.04 & $(0.04)$ & -0.01 & $(0.04)$ & -0.01 & $(0.04)$ & $0.10^{*}$ & $(0.04)$ & $0.10^{*}$ & $(0.04)$ \\
\hline NVQ 1 or below & - & - & -0.03 & $(0.05)$ & & & -0.07 & $(0.06)$ & & & $-0.10+$ & $(0.06)$ \\
\hline NVQ 2-3 & - & - & -0.06 & $(0.05)$ & & & -0.02 & $(0.05)$ & & & -0.07 & $(0.06)$ \\
\hline Jobless household & - & - & $0.06+$ & $(0.04)$ & & & $0.12^{* *}$ & $(0.04)$ & & & 0.01 & $(0.04)$ \\
\hline Rents & - & - & 0.01 & $(0.04)$ & & & 0.04 & $(0.04)$ & & & 0.03 & (0.04) \\
\hline Parameters of the growth curve & & & & & & & & & & & & \\
\hline Intercept mean & 0.06 & $(0.06)$ & $0.24^{* * *}$ & $(0.06)$ & $0^{5}+t$ & 0 & 0 & 0 & 0 & 0 & 0 & 0 \\
\hline Slope mean & 0.07 & $(0.13)$ & 0.15 & $(0.16)$ & 0.20 & $(0.17)$ & 0.27 & $(0.19)$ & 0.06 & $(0.17)$ & 0.26 & $(0.20)$ \\
\hline Intercept variance & $0.94^{* * *}$ & $(0.01)$ & $0.89^{* * *}$ & $(0.01)$ & $0.86^{* * *}$ & $(0.01)$ & $0.80^{* * *}$ & $(0.01)$ & $0.97^{* * *}$ & $(0.01)$ & $0.93^{* * *}$ & $(0.01)$ \\
\hline Slope variance & $0.97^{* * *}$ & $(0.01)$ & $0.97^{* * *}$ & $(0.01)$ & $0.99^{* * *}$ & $(0.01)$ & $0.98^{* * *}$ & $(0.01)$ & $0.99^{* * *}$ & $(0.01)$ & $0.98^{* * *}$ & $(0.01)$ \\
\hline Intercept-slope Covariance & $-0.34^{* * *}$ & $(0.04)$ & $-0.35^{* * *}$ & $(0.04)$ & $-0.41^{* * *}$ & $(0.04)$ & $-0.42^{* * *}$ & $(0.04)$ & $-0.22^{* * *}$ & $(0.03)$ & $-0.23^{* * *}$ & $(0.03)$ \\
\hline
\end{tabular}

tPredicted scores from a Latent trait model of five items mental health SF-36 questionnaire.

¥Three category self-rated health.

§Five category single item life satisfaction Likert scale.

ISignificant at $\mathrm{p} 0.1 ;{ }^{*}$ at $p<0.05 ;{ }^{* *}$ at $p<0.01 ;{ }^{* * *}$ at $p<0.001$

$\$$ †tParameter constrained to 0 .

Coef, standardised slope and intercept regression coefficients; NDC, New Deal for Communities; NVQ, National Vocational Qualification.

fit to the data than the models which assumed linearity. Estimated factor loadings indicate that for individuals experiencing change over time, the strongest impact for each outcome occurred between 2004 and 2006 ( $p<0.05$ for each outcome), after which the trajectories tended to flatten. The estimated factor scores were 2.7, 2.4 and 2.3, respectively, for mental
Figure 1 Predicted growth curves of: (1) living in rented accommodation, living in comparator areas, and both on mental health; (2) being educated up to equivalent National Vocational Qualification (NVQ) 1 level or less (including no formal qualification), living in comparator areas, and both on life satisfaction. Outcomes are factor scores from an item response theory model of five item Mental Health Inventory and single item life satisfaction indicator. Slope and intercept regression coefficients are standardised. Results based on 11648 observations (NDC, New Deal for Communities).
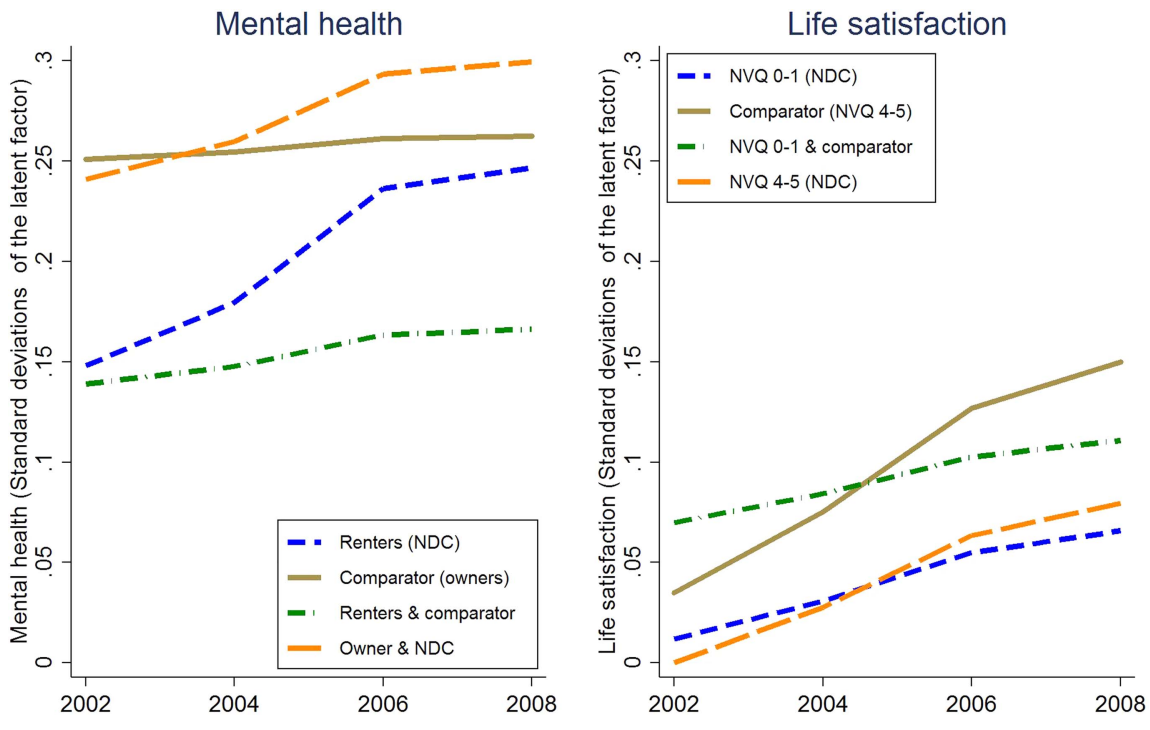
health, self-rated health and life satisfaction. Although the shape of the relationship between each outcome and follow-up time was non-linear, there was no clear evidence of an overall statistically significant change in outcomes. We explored this further by limiting the data to the period covering 2002-2006 but did not find evidence of a statistically significant change in outcomes in these models either (data available from the authors).

\section{CONCLUSION}

In this study, we found no improvement or worsening of mental health, self-rated health and life satisfaction among NDC residents as a whole, after controlling for their individual demographic and socioeconomic characteristics at baseline in 2002. Some evidence of positive change was found for specific groups within NDC areas which was not seen in comparator areas. Living in an NDC area appeared to mitigate the negative effect of baseline socioeconomic disadvantage on changes in mental health and life satisfaction, with respondents in poorer socioeconomic circumstances in NDC areas faring better than those in comparator areas. We also found that those who experienced a change in any of the three outcomes did so in a non-linear fashion-improvement occurred at a faster pace between 2004 and 2006, flattening out after this. This is potentially interesting as in other work undertaken as part of our study NDC residents and workers noted that there had been a change in policy towards the NDC programme around 2006 with greater central control being put in place in some areas.

\section{Strengths and limitations}

A strength of the analyses presented here is that it is the first time that assessment of a potential impact of the NDC intervention and, more generally, ABI has fully exploited longitudinal data, that is, taking into account data for 2002, 2004, 2006 and 2008 and using methods which appropriately take account of the structure of the data, individual differences in baseline outcomes and their change over time. It also utilised multiply-adjusted analysis to statistically control for demographic and socioeconomic effects on baseline levels and change over time in the outcomes. This analysis adjusted for the fact that residents of comparator areas tended to be better off than those in NDC areas.

On the contrary, contamination of comparator areas by NDC interventions cannot be excluded, ${ }^{14}$ and therefore conclusions of an absence of an overall NDC effect may be conservative. Additionally, other regeneration initiatives in NDC as well as comparator areas, such as Education Zones or Health Action Zones, ${ }^{29}$ may have influenced the outcomes. The fact that little is known about respondents who dropped out from the survey is another limitation, although recent work suggests that this may not be an important source of bias in this study. ${ }^{30}$ Areas were not randomised, and so we cannot rule out the possibility of selection into the NDC intervention group on the basis of characteristics that may influence health and health trajectories. At the same time, the qualitative and quantitative data available to us suggest that there are no plausible reasons to believe that systematic baseline differences in co-operation and interactions between residents and agencies would explain these findings (forthcoming). We were unable to examine intervention intensity and timing since we have evaluated the NDC programme as a holistic intervention rather than as individual projects. In this secondary analysis, we were limited in our choice of health outcomes and objectively assessed health indicators were not captured in the household surveys. Finally, the small sample sizes, particularly of residents in the comparator areas, as well as the high attrition rate, potentially reduce the power of our analyses.

\section{Implications for research and policy}

Our findings confirm some of the results previously obtained by the NDC evaluation team, which suggest a weak impact of the NDC intervention on the health of residents, which was explained by initial sociodemographic and health characteristics. ${ }^{17}$ Our findings add to this by showing that there was evidence of differential change in outcomes among specific subgroups. In particular, our findings suggest that the more disadvantaged residents in comparator areas may have experienced smaller improvements in mental health and life satisfaction than those in NDC areas. This finding tallies with our related work using cross-sectional data showing that the NDC may have contributed to a prevention of the widening of socioeconomic inequalities in health and some of its social determinants. ${ }^{31}$ The suggestion that the improvement in health outcomes experienced by some NDC residents may have slowed down after 2006 as the NDC initiative was subjected to significant changes from the centre also raises important questions for those involved in the implementation of ABIs. Further study should also examine the role played by differences in social cohesion

Table 3 Differentiated impact of NDC interventions by socioeconomic group

\begin{tabular}{|c|c|c|c|c|c|c|c|c|c|c|c|c|}
\hline & \multicolumn{6}{|c|}{ Mental healtht } & \multicolumn{6}{|c|}{ Life satisfaction‡ } \\
\hline & \multicolumn{2}{|c|}{ Model 3} & \multicolumn{2}{|c|}{ Model 4} & \multicolumn{2}{|c|}{ Model 5} & \multicolumn{2}{|c|}{ Model 3} & \multicolumn{2}{|c|}{ Model 4} & \multicolumn{2}{|l|}{ Model 5} \\
\hline & Coef & SE & Coef & SE & Coef & SE & Coef & SE & Coef & SE & Coef & SE \\
\hline \multicolumn{13}{|c|}{ Factors affecting changes in the outcome over time: slope regression coefficients } \\
\hline Comparator & $-0.11^{*}$ & 0.05 & 0.02 & 0.04 & -0.01 & 0.04 & 0.04 & 0.04 & 0.08 & 0.05 & 0.03 & 0.05 \\
\hline NVQ 1 or below & -0.03 & 0.05 & 0.03 & 0.03 & -0.03 & 0.05 & -0.07 & 0.06 & -0.06 & 0.06 & -0.07 & 0.06 \\
\hline NVQ 2-3 & -0.06 & 0.05 & & & -0.06 & 0.05 & $-0.10 \S$ & 0.06 & $-0.11 \S$ & 0.06 & $-0.11 \S$ & 0.06 \\
\hline Jobless household & $0.06 \S$ & 0.04 & 0.06 & 0.04 & 0.07 & 0.04 & 0.01 & 0.04 & 0.01 & 0.04 & 0.02 & 0.04 \\
\hline Rents & 0.01 & 0.04 & -0.00 & 0.04 & 0.00 & 0.04 & -0.02 & 0.04 & 0.03 & 0.04 & 0.03 & 0.04 \\
\hline Rents * Comparator & $0.09^{*}$ & 0.04 & & & & & -0.06 & 0.04 & & & & \\
\hline NVQ 1 or below * Comparator. & & & -0.07 & 0.04 & & & & & $-0.09^{*}$ & 0.05 & & \\
\hline Jobless household* Comparator & & - & & & -0.04 & 0.04 & & & & & -0.04 & 0.04 \\
\hline
\end{tabular}


and integration between NDC and comparator areas, as this may mitigate the effect of socioeconomic difference on health.

This study has demonstrated the use of latent growth models to evaluate complex ABIs. It benefited from a 6-year follow-up period, but this is a relatively short time frame in which to identify measurable changes in health, especially considering that some of the anticipated effects may only become visible in the long term. Future work should consider longer term impact on health, as well as compare with studies following a comparable design, such as the GoWell and the Well London regeneration initiatives, respectively, in Glasgow and London. Care should also be taken to improve the reliability of health indicators used in evaluation studies by, for example, avoiding single item instruments and including biomarkers where possible.

\section{What is already known on this subject}

- Socioeconomic disadvantage and poor health tend to concentrate in particular geographical areas, and targeted interventions such as the New Deal for communities (NDC) have been designed to reduce inequalities in the social determinants of health and hence have potential to improve health outcomes in these areas.

- Repeated cross-sectional analysis has provided evidence of a positive result from NDC interventions, especially in terms of aggregate area-based outcomes, while improvement in within-person health outcomes was more limited.

\section{What this study adds}

- The study provides evidence based on comprehensive multiply-adjusted analysis of within-person change in mental health, self-rated health and life satisfaction based on data from 2002, 2004, 2006 and 2008.

- While highly significant heterogeneity between individual health trajectories was observed, no overall pattern of positive or negative change over time in New Deal for Communities (NDC) areas was observed.

- We found evidence of an NDC impact, however, for certain subgroups living in the areas. Lower levels of education and household-level joblessness were associated with worse health trajectories in NDC areas as well as comparator areas, but more disadvantaged residents in NDC intervention areas experienced a greater improvement in mental health and life satisfaction than their counterparts in comparator areas. The statistical significance of these findings is limited.

- Where improvement in mental health or life satisfaction occurred, it did so in a non-linear fashion, with most of the change taking place before 2006, a point at which important changes occurred across the NDC programme governance.

\section{Twitter Follow Pierre Walthery at @PierreWalthery}

Acknowledgements The authors thank the NDC National Evaluation Team led by the Centre for Regional Economic and Social Research (CRESR) at Sheffield Hallam University and, in particular, Paul Lawless and Christina Beatty for their support. They would like to acknowledge funding support from the Department of Health Policy Research Programme and thank Christine McGuire for her advice and support throughout the life of the project. This is an independent report of research commissioned and funded by the Policy Research Programme in the Department of Health (Title: Evaluating the impact of New Deal for Communities on Health
Inequalities: Phase 2. Reference No: PR-IP-0509-0180063). The views expressed are those of the authors and not necessarily those of the Department of Health.

Contributors JP, MW, JN, MS and PW designed the study. PW collated the data and conducted data analysis; PW and MS drafted the paper; all authors contributed to interpreting the results, revised the draft and approved the final version.

Funding Department of Health. Grant/Award Number PR-IP-0509-0180063.

\section{Competing interests None.}

Provenance and peer review Not commissioned; externally peer reviewed.

Open Access This is an Open Access article distributed in accordance with the Creative Commons Attribution Non Commercial (CC BY-NC 4.0) license, which permits others to distribute, remix, adapt, build upon this work non-commercially, and license their derivative works on different terms, provided the original work is properly cited and the use is non-commercial. See: http://creativecommons.org/ licenses/by-nc/4.0/

\section{REFERENCES}

1 Acheson D, Barker D, Chambers J, et al. Independent inquiry into inequalities in health. Report. London: The Stationery Office, 1998.

2 Marmot M, Allen I, Goldblatt P, et al. Fair society, healthy lives: strategic review of health inequalities in England post-2010. The Marmot Review. London: University College London, 2010.

3 Fahmy E, Gordon D, Dorling D, et al. Poverty and place in Britain, 1968-99. Environ Plann A 2011;43:594-617.

4 ONS. Life expectancy at birth and at age 65 for local areas in England and Wales, 2010-12. Technical report. London: Office for National Statistics, Crown Copyright, 2013.

5 ONS. General health in England and Wales, 2011 and comparison with 2001. Technical report. London: Office for National Statistics, Crown Copyright, 2013.

6 Pickett K, Pearl M. Multilevel analyses of neighbourhood socioeconomic context and health outcomes: a critical review. J Epidemiol Community Health 2001;55:111-22.

7 Riva M, Gauvin L, Barnett T. Toward the next generation of research into small area effects on health: a synthesis of multilevel investigations published since July 1998. J Epidemiol Community Health 2007:61:853-61.

8 Cummins S, Stafford M, Macintyre S, et al. Neighbourhood environment and its association with self-rated health: evidence from Scotland and England. J Epidemiol Community Health 2005;59:207-13

9 Galea S, Ahern J, Rudenstine $S$, et al. Urban built environment and depression: a multilevel analysis. J Epidemiol Community Health 2005;59:822-7.

10 Kelaher M, Warr D, Tacticos T. Evaluating health impacts: results from the neighbourhood renewal strategy in Victoria, Australia. Health Place 2010;16:861-7

11 Aminzadeh K, Denny S, Utter J, et al. Neighbourhood social capital and adolescent self-reported wellbeing in New Zealand: a multilevel analysis. Soci Sci Med 2013;84:13-21.

12 Batty E, Beatty C, Foden M, et al. The New Deal for Communities experience: a final assessment. The New Deal for Communities Evaluation: Final report. Vol 7. London: Department for Communities and Local Government, Crown Copyright, 2010.

13 Beatty C, Brennan A, Foden M, et al. The New Deal for Communities experience: assessing. The New Deal for Communities Evaluation: Final report. Vol 6. London: Department for Communities and Local Government, Crown Copyright, 2010.

14 Lawless $\mathrm{P}$, Foden $\mathrm{M}$, Wilson I, et al. Understanding area-based regeneration: the New Deal for communities programme in England. Urban Stud 2010:47:257-75.

15 Batty E, Beatty C, Foden F, et al. Improving outcomes for people in deprived neighbourhoods: evidence from the New Deal for Communities Programme. Vol 4. The New Deal for Communities National Evaluation: Final report. London: Department for Communities and Local Government, Crown Copyright, 2010.

16 Pearson S, Batty E, Cook B, et al. Improving health outcomes in deprived communities. Evidence from the New Deal for Communities Programme. London: Department for Communities and Local Government, Crown Copyright, 2010.

17 Beatty C, Foden M, Lawless $\mathrm{P}$, et al. Transformational change? A synthesis of new evidence 2008/09. Vol 6. London: Department for Communities and Local Government, Crown Copyright, 2010.

18 Lawless $P$, Beatty C. Exploring change in local regeneration areas: evidence from the New Deal for Communities Programme in England. Urban Stud 2013;50 (5):942-58

19 Beard J, Cerdá M, Blaney S, et al. Neighborhood characteristics and change in depressive symptoms among older residents of New York City. Am J Public Health 2009;99:1308.

20 Macintyre S, Ellaway A, Hiscock R, et al. What features of the home and the area might help to explain observed relationships between housing tenure and health? Evidence from the West of Scotland. Health Place 2003;9:207-18.

21 Mason K, Baker E, Blakely T. Housing affordability and mental health: does the relationship differ for renters and home purchasers? Soc Sci Med 2013;94:91-7. 


\section{Other topics}

22 Subramanian S, Kim D, Kawachi I. Covariation in the socioeconomic determinants of self-rated health and happiness: a multivariate multilevel analysis of individuals and communities in the USA. J Epidemiol Community Health 2005;59:664-9.

23 Lindén-Boström M, Persson C, Eriksson C. Neighbourhood characteristics, social capital and self-rated health: a population-based survey in Sweden. BMC Public Health 2010;10:628.

24 IPSOS-MORI. New Deal for Communities Household Survey 2006, 2006.

25 Ware J, Sherbourne C. The MOS 36-Item Short-Form Health Survey (SF-36). i. Conceptual framework and item selection. Med Care 1992;30(6):473-83.

26 Duncan T, Duncan S, Strycker L. An introduction to latent variable growth curve modeling: concepts, issues, and applications. Mahwah, NJ: Lawrence Erlbaum, 2006.

27 Stoel R, Wittenboer G, Hox J. Methodological issues in the application of the latent growth curve model. In: Montfort K, Oud J, Satorra A, eds. Recent developments on structural equation models, mathematical modelling: theory and applications. Springer: Amsterdam, 2004:241-61.

28 Muthén B, Muthén L. MPlus user manual, 2008.

29 Rhodes J, Tyler P, Brennan A. New developments in area-based initiatives in England: the experience of the single regeneration budget. Urban Stud 2003;40 (8):1399-426.

30 Pearson S, Lawless P. Population mobility in regeneration areas: trends, drivers, and implications; evidence from England's new deal for communities programme. Environ Plann A 2012;44:2023-39.

31 Stafford M, Badland $\mathrm{H}$, Nazroo J, et al. Evaluating the health inequalities impact of area-based initiatives across the socioeconomic spectrum: a controlled intervention study of the New Deal for Communities, 2002-2008. J Epidemiol Community Health 2014;68(10):979-86. 